\title{
Algorithmic and Computer Software for Determination of Thread Tension After Guide Large Curvacity
}

\author{
V. Shcherban, N. Kolva, D. Egorov, A. Petko, Ju. Makarenko \\ Kyiv National University of Technologies and Design, Ukraine
}

\begin{abstract}
The conducted studies of the effect of the structure of the threads on the amount of tension when interacting with guides and working bodies of weaving machines and knitting machines, which have a large curvature in the zone of contact with the thread, established a mechanism for the process of increasing the tension of the thread after the guide by changing the radius of curvature of the guide and friction forces in the zone contact. It is proved that the increase in tension is explained by a change in the angle of coverage of the thread of a guide of large curvature, and for complex threads and yarns, the real angle of coverage will be greater than the calculated one, due to deformation of the thread diameter in the contact zone, and for monofilaments it is less than the calculated one due to bending stiffness. The sequential passage of the thread along the guides, from the entry zone to the formation zone of fabric and knitwear, leads to a stepwise increase in tension. In this case, the output parameter of the tension after the previous guide will be the input parameter for the subsequent guide, which makes it possible to use recursion when determining the tension in front of the formation zone.

In this regard, research on the computer implementation of the algorithm for determining the thread tension on technological equipment using recursion should be considered relevant.
\end{abstract}

Key words: dichotomy algorithm, tension, thread, recursion, guide, radius of curvature.

Introduction. Modeling the process of processing threads on weaving machines and knitting machines is to study the process of interaction of threads with the surfaces of the working bodies of technological equipment $[1-3 ; 7 ; 12 ; 11]$. The shape of the surface of the working bodies is close to a cylindrical surface $[4,5]$. Therefore, during the experiment, cylindrical rods of various diameters were used as guiding surfaces [6-10].

The increase in tension is explained by a change in the angle of coverage of the thread with a guide of large curvature, and for complex threads and yarns, the real angle of coverage will be greater than the calculated $\varphi_{P}$, due to deformation of the thread diameter in the contact zone, and for monofilaments less than the calculated $\varphi_{P}$ due to the modulus of bending stiffness $[2,5]$. The value of the modulus of stiffness for bending, for complex threads and yarns, is influenced by the value of their twist [5]. With an increase in the twist of the thread, the modulus of its bending stiffness also increases [4-7]. This can be explained by the fact that with an increase in twist, the specific pressure between individual filaments increases, which leads to an increase in frictional forces that prevent the movement of elementary fibers during bending [9-11]. 
In this regard, research on the computer implementation of the algorithm for determining the thread tension on technological equipment using recursion should be considered relevant.

The purpose of the article. Development of algorithmic and software for determining the tension of the thread after the guide of large curvature.

Results. The program for determining the tension of the thread after the guide of great curvature includes five forms: Tfrm1NN1 = class(TForm); Tfrm1NN2 = class(TForm); Tfrm1NN3 = class(TForm); Tfrm1NN4 = class(TForm) TF Errors = class(TForm). On the first form of the program (fig.1) the following elements are located: btn1NN1: TButton; lbl1NN1: TLabel; lbl2NN1: TLabel; lbl3NN1: TLabel; lbl4NN1: T Label; Image1: TImage.

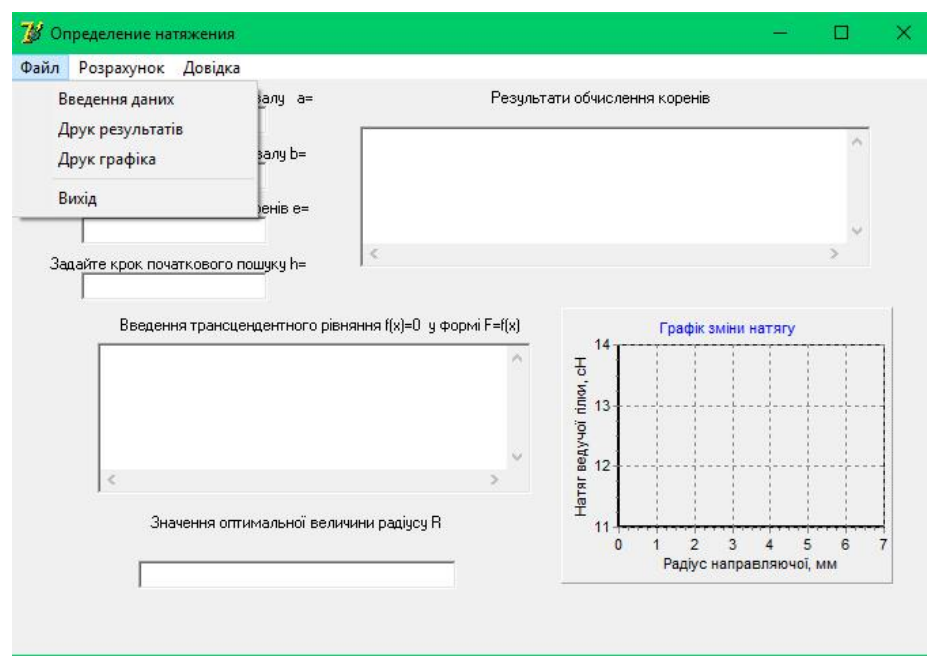

Figure. 1. The first form Tfrm1NN1 = class(TForm) program and the main form of the program for determining the tension of the thread after the guide

On the main form of the program Tfrm1NN2 = class(TForm) (fig.1) the main menu of the program is located MainMenu1: TMainMenu. It includes three menu sections: file; calculation; certificate. The file menu section includes the following sections: data entry; printing of results; graphic printing; Entrance. The calculation section includes the following subsections: calculate tension; build a schedule; calculate the optimum. This form has five onetime windows for entering data and displaying calculation results: edt1NN2: TEdit; edt2NN2: TEdit; edt3NN2: TEdit; edt4NN2: T Edit; edt5NN2: TEdit. One term window edt1NN2: TEdit designed to set the initial boundary of the search interval of the root of the transcendental equation to determine the tension of the thread after the guide of great curvature. One term window edt2NN2: TEdit designed to set the final boundary of the search interval of the root of 
the transcendental equation. One term window edt3NN2: TEdit designed to specify the accuracy of calculating the roots of the transcendental equation. One term window edt4NN2: TEdit designed to set the initial step in the iterative process. One term window edt5NN2: TEdit designed to display the value of the optimal value of the radius $R$ guide large curvature.

Many time window Memo1: TMemo designed to introduce a transcendental equation in the form $F=f(P)$. Many time window mem1NN2: TMemo designed to determine the results of calculations of the roots of the transcendental equation. This window displays the values of the tension of the leading branch of the thread after the guide of large curvature depending on the radius of curvature $R$.

When activating the data entry unit, file menu section, the procedure is performed procedure Tfrm1NN2.n2NN2Click(Sender: TObject). This activates the form Tfrm1NN4 = class(TForm). This form is designed to enter the necessary data to calculate the thread tension (fig. 2).

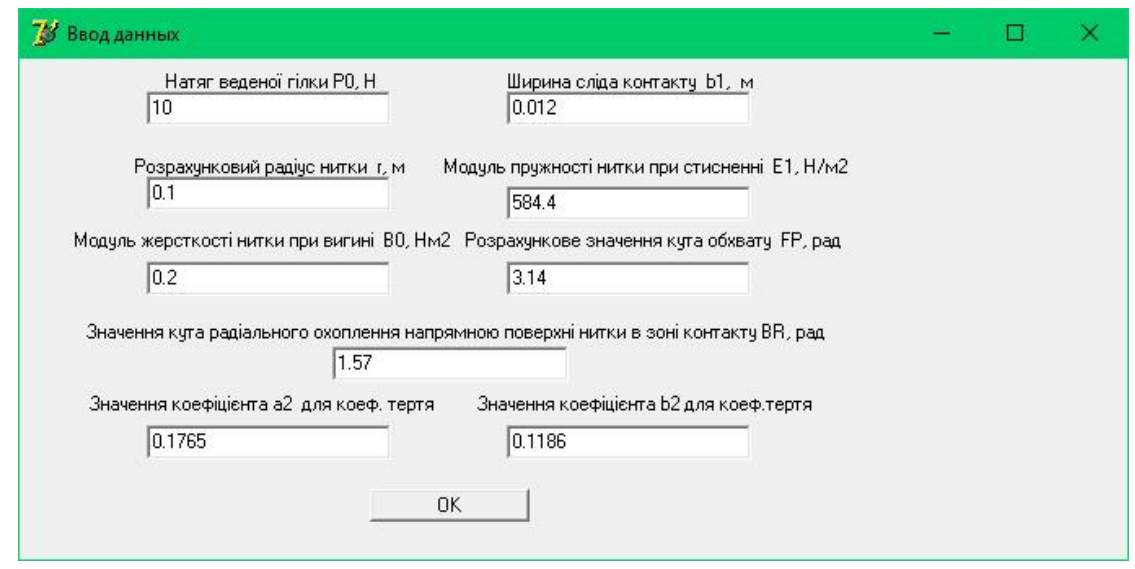

Figure. 2. Form Tfrm1NN4 = class(TForm) to enter data to calculate the thread tension

One term window edt2NN4: TEdit designed to introduce the tension of the driven branch $P_{0}$ to the guide. One term window edt3NN4: TEdit designed to enter the value of the width of the contact trace $b_{1}$ threads on the guide. One term window edt4NN4: TEdit designed to enter the value of the calculated radius $r$ cross section of thread or yarn. One term window edt5NN4: TEdit designed to enter the value of the modulus of elasticity of the thread or yarn during compression $E_{1}$. One term window edt6NN4: TEdit designed to enter the value of the modulus of stiffness of the thread or yarn when bending $B_{0}$. One term window edt7NN4: TEdit 
designed to enter the value of the calculated value of the angle of coverage of the guide $\varphi_{P}$. This angle is determined provided there is no deformation of the cross section of the thread or yarn in the area of contact with the guide and the stiffness of the thread to bend. One term window Edit1: TEdit designed to enter the value of the angle of radial coverage of the guide surface of the thread in the contact area $\delta$. One time window edt8NN4: TEdit, edt9NN4: TEdit designed to enter the value of empirical coefficients $a_{2}, b_{2}$.

Procedure procedure Tfrm1NN2.n7NN2Click(Sender: TObject) designed to perform the calculation of thread tension.

As an algorithm for determining the root of the transcendental equation, we will use the method of dividing the segment in half (dichotomy method). The program allows you to determine the tension of the thread after the guide for different values of the radius of curvature $R$ guide large curvature. The program implements two cycles. The first allows you to determine the tension of the thread after the guide of large curvature in the form of a torus for a fixed value of the radius of curvature $R$ guide of large curvature in the form of a torus. The outer cycle provides a change in the radius of curvature at the selected interval, the value of which is due to the design of the individual guides of the circular knitting machine of large diameter.

When performing the procedure procedure Tfrm1NN2.n7NN2Click(Sender: TObject) the results are displayed sequentially in a multi-term window mem1NN2: TMemo.

Execution of procedure procedure Tfrm1NN2.n8NN2Click(Sender: TObject) (fig.3a) allows you to build a graphical dependence of the value of the tension of the leading branch of the thread depending on the radius of curvature $R$ guide large curvature. The value of the interval of changing the radius of the guide can be changed programmatically.

A computer program allows you to determine the radius of curvature $R$ guide large curvature, at which the tension of the leading branch of the thread will be minimal. A procedure has been implemented for this purpose procedure Tfrm1NN2.n9NN2Click(Sender: TObject).

The input data for the implementation of the algorithm for dividing the segment in half is carried out using the following software operators: Val (edt1NN2.Text,a,code); Val(edt2NN2.Text,b,code); Val(edt3NN2.Text,e,code); Val(edt4NN2.Text,h,code). 
When you enter a transcendental equation in a multi-term window Memo1: TMemo transcendental equation in form $F=f(P)$ the program implements a translator using reverse Polish records. This is done using a separate unit Synt module. This module in the program is implemented without a form.

The TF Errors = class (TForm) form is used to control the input of information into the multi-term window Memo1: TMemo and to correct input errors.

Fig. $3 b$ presents the results of the program for determining the amount of tension of the leading branch of the thread depending on the radius of curvature of the guide of large curvature.

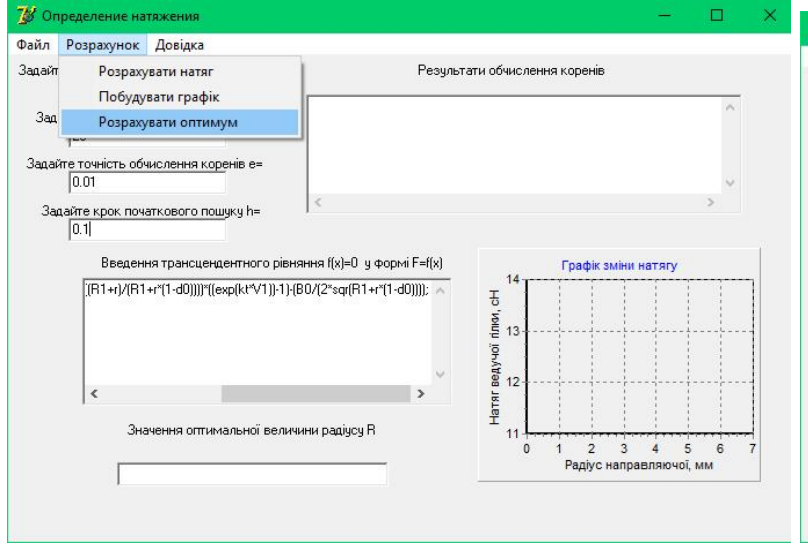

a

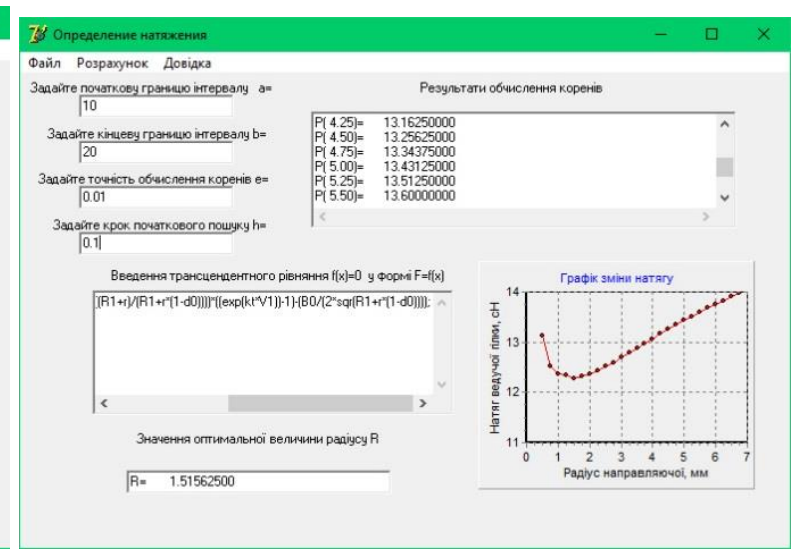

$\mathrm{b}$

Figure. 3. Procedure Tfrm1NN2.n8NN2Click (Sender: TObject) and program results for determining the amount of tension of the leading branch of the thread.

Conclusions. An algorithm and a computer program for determining the value of tension when the thread interacts with the guides in the form of a torus feed system of circular knitting machines based on the numerical implementation of the algorithm for half-segment separation in solving transcendental equations and developed a translator using inverse Polish records.

\section{References}

1. Scherban V.Yu., Murza N.I., Kirichenko A.N., Sholudko M.I.. Overall performance of compensators of the filament of knitted cars. Khmelnitskyi. Herald of Khmelnytskyi national university. Technical sciences. Khmelnitskyi.2017. Volume 245. Issue 1. pp.83-86.

2. Slizkov AM, Shcherban V.Yu., Kizimchuk O.P. Mechanical technology of textile materials. Part II. (Weaving, knitted and non-woven production): textbook / A.M. Slizkov, V.Y. Shcherban, O.P. Kyzymchuk. K.: KNUTD, 2018. 276 p. 
3. Scherban V. Interaction yarn guide surface/V.Scherban, M. Sholudko, V. Kalashnik, O. Kolisko//Intellectual Archive, Toronto: Shiny World Corp., Richmond Hill, Ontario, Canada. - May 2015. Volume 4, Number 3, pp. 10-15.

4. Scherban V.Yu., Murza N.I., Kirichenko A.N., Sholudko M.I.. Comparativec analysis of work of natyazhiteley of filament of textile machines. Khmelnitskyi. Herald of Khmelnytskyi national university. Technical sciences. Khmelnitskyi.2016. Volume 243. Issue 6. pp.18-21.

5. Shcherban V.Yu., Volkov O.I., Shcherban Yu.Yu. Mathematical models in CAD equipment and technological processes of light and textile industries. - K .: KNUTD, 2003. $600 \mathrm{p}$.

6. Scherban V. Basic parameters of curvature and torsion of the deformable thread in contact with runner/V. Scherban, N.Murza, A.Kirichenko, O. Kolisko, M. Sholudko //Intellectual Archive, Toronto: Shiny World Corp., Richmond Hill, Ontario, Canada. - Nov/Dec - 2016. Volume 10, Number 2, pp. 18-23.

7. Scherban V. Kinematics of threads cooperates with the guiding surfaces of arbitrary profile /V. Scherban, N. Murza, O. Kolisko, M. Sheludko, I. Semenova //Intellectual Archive, Toronto: Shiny World Corp., Richmond Hill, Ontario, Canada. May/June 2016, Volume 5, Number 3, pp. 23-27

8. Scherban V. Equalizations of dynamics of filament interactive with surface/V. Scherban, G. Melnik, A.Kirichenko, O. Kolisko, M. Sheludko//Intellectual Archive, Toronto: Shiny World Corp., Richmond Hill, Ontario, Canada. January/February 2017, Volume 6, Number 1, pp. 2226.

9. Scherban V.Yu., Kalashnik V.Yu., Kolisko O.Z., Sholudko M.I.. Investigation of the influence of the thread material and the anisotropy of friction on its tension and the shape of the axisю. Khmelnitskyi. Herald of Khmelnytskyi national university. Technical sciences. Khmelnitskyi.2015. Volume 223. Issue 2. pp.25-29.

10. Computer systems design: software and algorithmic components / V.Y. Shcherban, O.Z. Kolisko, G.V. Melnyk, M.I. Sholudko, V.Y. Kalashnik. K.: Education of Ukraine, 2019. 902 p.

11. Algorithmic, software and mathematical components of CAD in the fashion industry / V. Yu. Scherban, O.Z. Kolisko, M.I. Sholudko, V. Yu. Kalashnik. K.: Education of Ukraine, 2017. $745 \mathrm{p}$.

\section{Translation of references to the original language}

2. Слізков А.М., Щербань В.Ю., Кизимчук О.П. Механічна технологія текстильних матеріалів. Частина II. (Ткацьке, трикотажне та неткане виробництво): підручник / А.М.Слізков, В.Ю.Щербань, О.П.Кизимчук. К.:КНУТД, 2018. 276 с.

5. Щербань В.Ю., Волков О.И., Щербань Ю.Ю. Математические модели в САПР оборудования и технологических процессов легкой и текстильной промышленности. К.: КНУТД, 2003. 600 c. 